\title{
POETRY
}

\section{Once woken}

The phone rings

Jarred awake

By a breathless medical resident

The cat jumps down

Scrabbling across the

Bare floor

There was a code blue

On your patient

He coded?

Yes, he coded

Ask a thoughtful question:

He coded?

Yes, he coded

But we got him back

Thank God for that

Glowing eyes

In the hallway

The cat sits, waiting expectantly

You said, always call

Even when

There is nothing left to do

I wonder why

A historical imperative perhaps

Passed down through the ages

That the doctor should be called

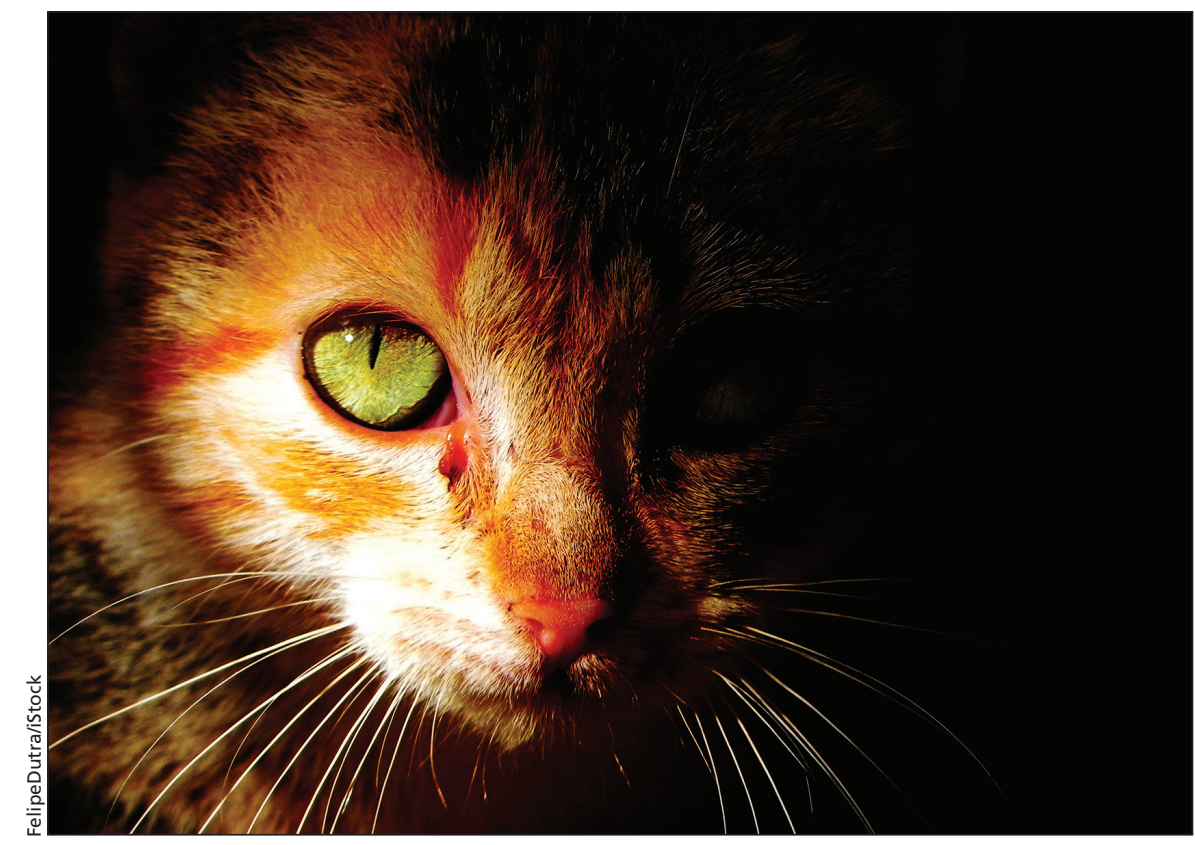

The cat has gone

I say

Thanks and

Good night

My secret

Which I do not share:

Once woken, I will not

Sleep again.
Thomas E. MacMillan MD MSc

Division of General Internal Medicine, Toronto Western Hospital, University Health Network, Toronto, Ont.

This poem placed first in the poetry category of The 2015 Humanities Poetry and Prose Contest, jointly sponsored by ARS Medica and $C M A J$.

CMAJ 2015. DOI:10.1503/cmaj.150526 